\title{
Aspiration of anchovy paste liquid from a multilobulated liver space-occupying lesion in a patient presenting with fever and weight loss: early stage amoebic liver abscess
}

\author{
Loukas Kakoullis (1) , ${ }^{1,2}$ Linos Hadjihannas, ${ }^{1}$ Stylianos Louppides, ${ }^{1}$ George Panos (1) 1,3
}

'Department of Internal Medicine, Nicosia General Hospital, University of Cyprus Medical School, Nicosia, Cyprus ${ }^{2}$ Department of Respiratory Medicine, University of Patras, Patras, Achaia, Greece ${ }^{3}$ Infectious Diseases Section, University General Hospital of Patras, Patras, Achaia, Greece

\section{Correspondence to}

Professor George Panos; george.panos.frcp@gmail.com

Accepted 10 January 2020

\section{DESCRIPTION}

A 57-year-old man presented with a 10-day history of fever with rigours and weight loss. The fever manifested during the afternoon hours, reaching up to $39.5^{\circ} \mathrm{C}$ and was followed by profuse sweating. The patient reported that he had lost $7 \mathrm{~kg}$ during this time. He did not report any abdominal pain and on direct questioning he denied having a prodrome of diarrhoea; further, he could neither recall in his history a bout of diarrhoea lasting several (up to 6 weeks) or recurring diarrhoea over the previous years. He had been empirically prescribed ciprofloxacin and doxycycline by his primary care physician for 5 days, without the improvement of symptoms. He denied any travel to an endemic area. Physical examination was unremarkable. The liver edge was not palpable, and no tenderness was noted on palpation of the right hypochondrium.

Laboratory investigations were significant for increased inflammatory markers, specifically white cell count 12.000 cells $/ \mathrm{mL}$, erythrocyte sedimentation rate $66 \mathrm{~mm} / \mathrm{h}$ and $\mathrm{C}$ reactive protein $150.8 \mathrm{mg} / \mathrm{L}$, and a mild elevation of liver enzymes, specifically alanine aminotransferase $73 \mathrm{IU} / \mathrm{L}$, aspartate aminotransferase $48 \mathrm{IU} / \mathrm{L}$, alkaline phosphatase $261 \mathrm{IU} / \mathrm{L}$ and gamma-glutumayltransferase $172 \mathrm{IU} / \mathrm{L}$

The patient on admission was prescribed piperacillin/tazobactam, covering an extended spectrum as compared with his previous empirical antibiotic regimen, including Gram-negative, Gram-positive and anaerobic bacteria. He subsequently underwent an abdominal ultrasound, which revealed multiple confluent hypoechoic lesions without wall echoes (non-encapsulated) in the right lobe of the liver. He then underwent a CT scan, which revealed the presence of multiple confluent hypodense lesions in the right lobe of the liver (segments IV and V)
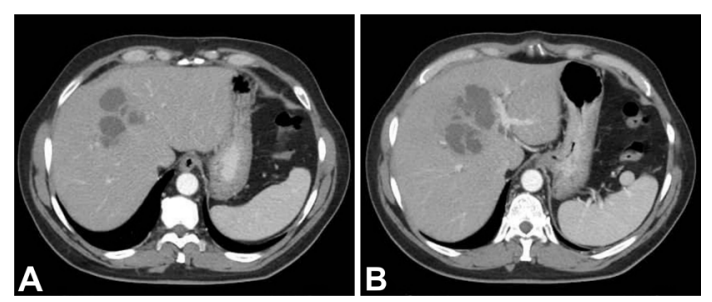

Figure 1 The multiple abscesses can be appreciated in the right lobe $(A)$, which confluence near the level of porta hepatis $(B)$ to form a multilobulated abscess.

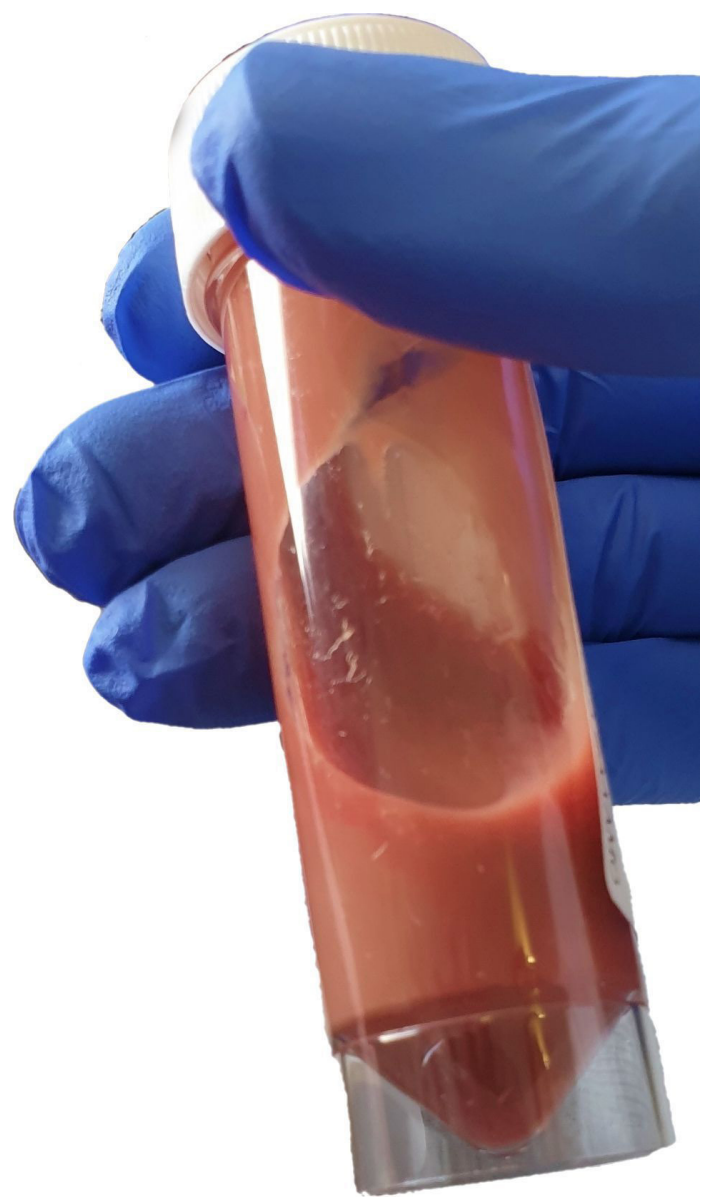

Figure 2 A sample of the aspirated abscess fluid, reminiscent of the classic descriptions of the 'anchovy paste' liquid.

which displayed reduced uptake of IV contrast. The lesions formed a multilobulated mass measuring $7.8 \mathrm{~cm}$ in diameter (figure 1). The patient was prescribed metronidazole $500 \mathrm{mg}$ IV three times a day on a tentative diagnosis of amoebic liver abscess and continued piperacillin/tazobactam $4.5 \mathrm{~g}$ four times a day IV pending final diagnosis. The patient did not defervesce for 72 hours, at which point percutaneous aspiration of the abscess was requested, which was performed on the earliest available appointment on the eighth day of hospitalisation by an interventional radiologist.

The patient underwent a CT-guided aspiration of the mass, which produced a red-brown coloured 
liquid (figure 2), reminiscent of the classic descriptions of the anchovy paste liquid recovered from the amoebic liver abscess. After the aspiration of the abscess, the patient defervesced within 3 days, after which piperacillin/tazobactam was discontinued.

Cultures of the liquid were negative for the presence of bacteria, whereas direct microscopy did not reveal the presence of amoeba or other microorganisms. Stool samples taken on three consecutive days were negative for the presence of ova or parasites. Nevertheless, ELISA for antiamoebic antibodies was positive.

The patient's condition improved, and he was discharged on metronidazole for an additional 3 weeks. Follow-up examination and CT scan 1-month postdischarge revealed resolution of symptoms and regression of the lesion, respectively.

Amoebic liver abscess usually presents as a solitary lesion. Nevertheless, early lesions can be multifocal, presenting as several micro-abscesses. ${ }^{1}$ Patients can usually be managed conservatively, with antibiotic therapy alone. However, aspiration of the abscess may be warranted either for diagnostic purposes, in cases where the diagnosis is not clear, or therapeutic purposes, such as in cases of large left lobe abscess, clinical deterioration, imminent danger of rupture or when the patient has not improved after 4 days of metronidazole treatment, ${ }^{2}$ although some authorities

\section{Learning points}

- Patients with amoebic liver abscess can present solely with fever and weight loss, whereas abdominal pain or a history of travel in endemic areas and recent bouts of diarrhoea may not be present.

- Although not always warranted, in cases where antibiotic treatment does not lead to defervescence within 4 days, aspiration of the abscess can lead to resolution of symptoms.

- A high degree of clinical suspicion is required for the diagnosis of an amoebic liver abscess to be made in countries in which the disease is not endemic, such as Cyprus. recommend percutaneous aspiration to be considered if there is no response after $48-72$ hours, despite that response to treatment may, in fact, occur within the first 96 hours.

In our case, a luminal amoebicide such as paromomycin (indirect-acting luminal amoebicide) or diloxanide-furoate (direct-acting luminal amoebicide) was not administered, as these medications are not available on demand in our setting can only be obtained after direct import from a foreign country, after 5-7 days post prescription; our patient defervesced 9 days post metronidazole administration. Additionally, the patient on direct questioning denied having diarrhoea, did not excrete ova, trophozoites or parasites on three consecutive stool examinations and had already received 5 days of doxycycline, an indirectacting luminal amoebicide. Had trophozoites been identified in stool, paromomycin or another luminal amoebicide would have been mandatorily administered. Metronidazole (a tissue amoebicide and to a lesser extent a luminal amoebicide) proved to be an effective treatment in our patient; metronidazole was continued until the estimated time of disappearance of the lesion, subsequently confirmed by a CT scan.

Contributors LK: evaluated the patient, obtained informed consent and drafted the manuscript. LH: evaluated the patient and drafted the manuscript. SL: evaluated the patient and drafted the manuscript. GP: evaluated the patient, drafted and reviewed the manuscript.

Funding The authors have not declared a specific grant for this research from any funding agency in the public, commercial or not-for-profit sectors.

Competing interests None declared.

Patient consent for publication Obtained.

Provenance and peer review Not commissioned; externally peer reviewed.

\section{ORCID IDs}

Loukas Kakoullis http://orcid.org/0000-0001-6245-1569

George Panos http://orcid.org/0000-0002-2712-5909

\section{REFERENCES}

1 Ximénez C, Morán P, Rojas L, et al. Novelties on amoebiasis: a neglected tropical disease. J Glob Infect Dis 2011;3:166.

2 Stanley SL. Amoebiasis. Lancet 2003;361:1025-34.

Copyright 2020 BMJ Publishing Group. All rights reserved. For permission to reuse any of this content visit

https://www.bmj.com/company/products-services/rights-and-licensing/permissions/

BMJ Case Report Fellows may re-use this article for personal use and teaching without any further permission.

Become a Fellow of BMJ Case Reports today and you can:

- Submit as many cases as you like

- Enjoy fast sympathetic peer review and rapid publication of accepted articles

- Access all the published articles

- Re-use any of the published material for personal use and teaching without further permission

Customer Service

If you have any further queries about your subscription, please contact our customer services team on +44 (0) 2071111105 or via email at support@bmj.com.

Visit casereports.bmj.com for more articles like this and to become a Fellow 